\title{
Exploiting Computer Technologies for Military Integrated Mission Planning
}

\author{
Peter Thunholm \\ Swedish National Defence College \\ Peter.thunholm@fhs.se
}

\author{
Mervyn Cheah \\ Singapore Technologies Electronics \\ mervyncheah@stee.stengg.com
}

\begin{abstract}
Motivation - To initially test a new integrated mission planning process (IMPP) designed to allow echelons of command to collaborate while working distributed through the use of a collaborative mission planning system called MissionMate (MM). Research approach - Case-study approach with observations and questionnaires. Findings/Design - The process and technology (IMPP+MM) worked despite a minimum initial training effort. Problems to be addressed in follow-up studies are: To establish a minimum system proficiency level among users; to create a mindset among staff officers allowing true collaboration across echelons of command, and to accept distributed collaboration as a norm instead of face-to-face meetings. Research limitations/Implications - This was the first of several planned studies to develop IMPP+MM. The qualities of the new approach have not yet been assessed experimentally. Take away message - The IMPP+MM model has potential to increase the effectiveness of integrated planning between echelons, both by saving time and increasing shared understanding of the plan.
\end{abstract}

Keywords

Military integrated planning, collaborative C2 software.

\section{INTRODUCTION}

Modern military planning doctrines are now adopting parallel planning across hierarchical levels, with the intent to save time (e.g. US Army, 2005). As a consequence, collaborative technologies, from chat to desktop sharing capabilities, are now popular software to enable information sharing and exchange of ideas among staff. Findings from recent studies suggests that in order to seed a good integrated planning process, new planning models that facilitate a synergistic working process across the echelons of command with the enabling collaborative technologies will have to be developed (Cheah, Thunholm, Chew, Wikberg, Andersson, Danielsson, 2005; Thunholm, Cheah, Fong, Tee, Chew, Larsson, 2006).

The purpose of this study was to initially test a new integrated planning model. Called as the Integrated Mission Planning Process (IMPP; Thunholm, 2008), it is designed to allow echelons of command to work together while distributed through the use of a collaborative mission planning system called MissionMate (MM). MM is a suite of 3 software consisting of a synchronous multi-workspace collaborative map and graphic software, a web-based document management software and a multi-party video conferencing software. It is developed by Singapore Technologies Electronics (Info-Software Systems), and adapted for the Swedish National Defence College specifications. The study was the first in a series of research aimed to fulfil the Swedish Armed Forces' objective of realizing a net-centric Flexible Command Posts (FCP) 2014 vision. This poster describes the result of an initial evaluation of the IMPP+MM planning model conducted during a military planning and execution staff exercise.

\section{METHOD}

The Participants in this study were 85 students (Army captains and majors) attending an army tactics course at Swedish National Defence College. They were organized into a Land Component Command (LCC) staff and two Mechanized Brigade (BDE) staff units. Subordinated units to the Brigades were role played by other students. The LCC was given directives to conduct a peace support/peace enforcement operation in an urban area of the fictitious country of Svealandia for this study. The study employed a case-study design and data was collected through on-site observations and online surveys on two separate occasions (after the planning phase and after the execution phase).

The exercise was carried out over 2 phases; with the first phase for deliberate mission planning, stretched over two consecutive weeks, and the second phase of about 4 days was focussed on executing the plan to determine if the IMPP and MM could assist the participants in conducting effective and timely re-planning across echelons of command. As part of the students' course schedule, only 2 hours of formal training on MM were allotted as compared to a prescribed 
norm of 2 days. This was however, compensated with on-the-job coaching to all participants by software engineers at a ratio of 1-2 engineers per headquarters during the first phase of the study.

\section{RESULTS AND DISCUSSION}

The overall result of the study showed that the combined integrated planning process and systems approach (IMPP + $\mathrm{MM}$ ) worked, but not fully as desired. One main reason identified were attributed to insufficient formal training for students to synergistically use both IMPP and MM effectively. For users with a high level of computer literacy, 2 hours of training supplemented with on-the-job coaching was good enough. Those users rated the usability and the effectiveness of the system as being good. For users with a low level of computer literacy, they reported adversely to the short 2 hours of training by not evaluating the system as highly as the other participants. In addition, some officers holding staff leading positions felt that they needed more formal training and guidance on how to effectively apply the IMPP.

A common problem in conducting studies with military personnel on courses is that there is often little time allowed for complete training of systems prior to the conduct of the study. It is therefore important that the systems are designed to be user friendly and intuitive in usage, allowing users to quickly familiarize and get acquainted with the key functionalities of the system. Some students showed greater interest and ability than others to use the MM more proficiently. The software engineers would often exemplify these class of students during the day debriefs and gave them extra attention on how to exploit the system more efficiently for integrated planning which were not initially taught during formal training sessions. On average, the students' overall proficiency with the system increased during the course of the study.

There was a natural tendency for participants, especially under time-pressure, to conduct face-to-face discussions around a paper map and not through the MM system. As face-to-face meetings are very much a predominant behaviour, Staff officers found it difficult to replace traditional staff conferences with video conferences, although that worked well too once they started to get use to it.

The IMPP manual instructs the higher and lower staff to plan together simultaneously. As an example, one of the prescribe step was for the development of the initial mission endstate as one of the first activities over online collaboration between the LCC and BDE. However, during the mission planning stage, the LCC staff often preferred to develop the preliminary endstate through internal conferencing within the LCC before inviting the BDE staff to discuss. Such sequential development of the endstate led to a form of "planning guidance" engagement with the BDE staff instead of equal contribution of idea generation to the initial endstate. As we see it, this is also another form of training tradition based on the fact that hierarchical formed headquarters are not used to exchange and form ideas together, because it is seldom feasible due to different locations.

The overall conclusions are that the IMPP+MM model has the ability and potential to increase the effectiveness of integrated planning between echelons both by saving time and increasing shared understanding of the plan. However, some working procedures and habits in current staff work needs to be worked on, for example to inculcate participants to habitually use collaborative technologies, even in their daily routines at work, instead of the traditional practice of discussing eye-to-eye over a paper map.

\section{REFERENCES}

Cheah, M., Thunholm, P., Chew, L. P., Wikberg, P., Andersson, J. \& Danielsson, T. (2005). C ${ }^{2}$ Team Collaboration Experiment - A Joint Research by Sweden and Singapore on Teams in a CPoF environment. Proceedings to 10th International Command and Control Research and Technology Symposium: The Future of Command and Control, June 13-16, McLean, VA. Command and Control Research Program (CCRP), Washington, D.C.

Thunholm, P., Cheah, M., Fong, G., Tee, C.A., Chew, L. P., \& Larsson S-Å (2006). C ${ }^{2}$ Team Collaboration Experiment II - A Study on Teams in a CPoF environment. Proceedings to 11th International Command and Control Research and Technology Symposium: Coalition Command and Control in the Networked Era. September, Cambridge, U.K. Command and Control Research Program (CCRP), Washington, D.C.

Thunholm, P. (2008) En studie av integrerad planering med hjälp av ett modernt tekniskt ledningssystem. [A study of integrated mission planning enabled by modern C2 Collaboration software]. Unpublished Annual Project Report, Swedish NDC report \# 1081/7:40. Stockholm: Swedish National defence College.

US Army (2005). Field Manual (FM) 5-0. Army Planning and Orders Production. Headquarters Department of the Army, Washington, DC. 